pear significant or trifling, depending upon the reader's mind set. But these particular statistics do recall a point made several times on these pagesthat it is not the length of stay that is necessarily responsible for rising health care costs. In our opinion, the high cost of inpatient admission relates directly to the number of diagnostic and therapeutic procedures performed purely on the basis of fear. If something goes wrong, will the question "You mean that you didn't even order a CAT scan?" be posed in the courtroom?

Health care costs will never be controlled until the practice of defensive medicine is reduced. As long as professional liability claims continue to escalate, million-dollar settlements persist, and sky-high insurance rates soar ever upward, the cost of hospital care also will continue to rise.

To the best of our knowledge, there has never been a study to assess the cost of defensive medicine. We need to gain an approximate calculation of this burden on the health care system. The price would, no doubt, be surprisingly high. Until the bottom line of this expense is considered and relieved, the high cost of inpatient medical care will continue unabated.

GEORGE W. NORTHUP, D.O., FAAO

\section{In my opinion}

From time to time, we have received articles which express personal opinions on many topics. They are often too long to publish as a "Letter to the Editor" and too short to publish as an article. In response to this editorial quandary, THE Do has launched a new section for these commentaries-aptly called "In My Opinion." Without exception, the articles will be subjected to the usual editing process and their acceptance or rejection will be the sole responsibility of the editors. The articles will bear the name of the author and represent his or her reflective opinion on matters of interest and concern to the profession.

"In my opinion" will not necessarily be a monthly feature. However, if the amount of material received in the past is any indication, we believe that the column will appear frequently.

The first article to be published in this new section of THE DO is written by AOA trustee and chairman of the AOA Editorial Policy Committee, William G. Anderson, D.O., who shares his ideas on quality assurance in the osteopathic profession. His comments were originally presented at the national seminar of the American College of Utiliza- tion Review Physicians last October. They will appear in March.

Dr. Anderson and others whose opinions will be published on these pages do not seek or expect universal agreement with all matters proposed. But they do invite feedback, constructive criticisms, and the opinions of others in our professional family.

GEORGE W. NORTHUP, D.O., FAAO

\section{editorial comment}

Intravenous feedings of vitamins $A$ and $E$ may help to prevent retinopathy and bronchopulmonary dysplasia in premature babies, according to Harry L. Greene, M.D., professor of pediatrics at Vanderbilt University School of Medicine in Nashville.

Dr. Greene, who presented his findings at the Bristol-Myers Symposium on Nutrition Research, has two difficulties to overcome with this therapy. First, vitamin A appears to be destroyed by light, and neonate nurseries are always well lighted. Second, because the vitamin A mixture tends to stick to the plastic intravenous tubing, only 10 to 15 percent of the vitamin actually reaches the babies. The researcher is working on a lipid preparation that would correct both problems.

All exercise programs are not created equal, at least as far as spinal bone mineral density is concerned. Researchers at the University of California-San Francisco used computed tomography to measure spinal bone density in 28 men who pursued various exercise programs and in 18 sedentary individuals.

Results showed that men who combined weight training with aerobic exercise had the greatest spinal bone density. Those who used only free weights or "resistance" equipment ranked second, followed by those with only an aerobics program, such as jogging or "jazzercise." Nonexercisers had the lowest spinal bone density.

Monosodium glutamate (MSG) may be getting a bum rap as the culprit of the so-called "Chinese restaurant syndrome." For more than a decade, the flavor enhancer has been blamed for a burning, tightness, or numbness around the face, neck, or chest in patrons who eat Chinese cuisine or other foods that contain the seasoning.

A researcher at George Washington University 
A Clear Approach To

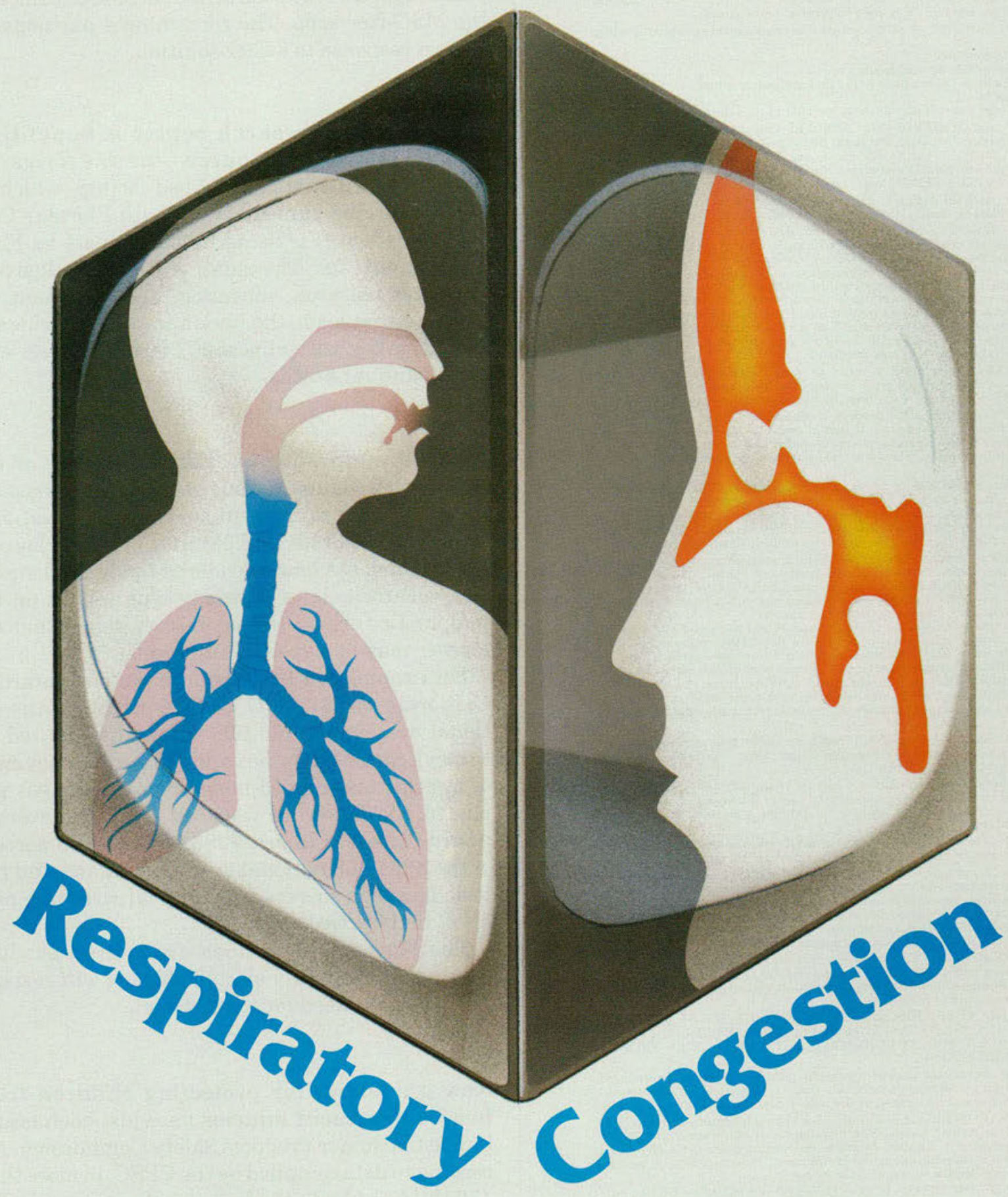

GUAIFED GUAIFED-PD

Muro Pharmaceutical Inc.

Tewksbury, MA O1876-9987 USA 


\section{GUAIFED GUAIFED-PD}

GUAIFED $^{\circ}$-PD CAPSULE. A blue and clear capsule containing white beads Each capsule contains:

Pseudoephedrine hydrochloride

in a specially prepared base to provide prolonged action

$300 \mathrm{mg}$

designed for immediate release to provide rapid action.

GUAIFED $^{\circ}$ CAPSULE. A white opaque and clear capsule containing white beads.

Each capsule contains:

Pseudoephedrine hydrochloride

$120 \mathrm{mg}$

in a specially

$250 \mathrm{mg}$

designed for immediate release to provide rapid action

GUAIFED $^{*}$ and GUAIFED ${ }^{*}$-PD CAPSULES also contain as inactive ingredients: Benzyl Alcohol, Butyl Paraben, Edetate Calcium Disodium, Gelatin, Methyl Paraben, Pharmaceutical Glaze, Propyl Paraben, Sodium Lauryl Sulfate, Sodium Propionate, Starch, Sucrose. Titanium Dioxide, FD\&C Blue "1 (GUAIFED-PD only) and other ingredients.

GUAIFED $^{\circ}$ and GUAIFED $^{\circ}$-PD contains ingredients of the following GUAIFED and GUAIFED
therapeutic classes: nasal decongestant and expectorant.

CLINICAL PHARMACOLOGY: Pseudoephedrine hydrochloride is a sympathomimetic which acts predominantly on alpha adrenergic receptors in the mucosa of the respiratory tract, producing vasoconstriction and has little action on beta receptors. It therefore functions as an oral nasal decongestant with minimal CNS stimulation. Pseudoephedrine hydrochloride also in creases sinus drainage and secretions. Guaifenesin is an expectorant which increases the output of phlegm (sputum) and bronchial secretions by reduc ing adhesiveness and surface tension. The increased flow of less viscid secretions promotes ciliary action and changes a dry, unproductive cough to one that is more productive and less frequent.

INDICATIONS: For temporary relief of nasal congestion and dry non productive cough associated with the common cold and other respiratory allergies. Helps drainage of the bronchial tubes by thinning the mucus. CONTRAINDICATIONS: This product is contraindicated in patients with known hypersensitivity to any of Its ingredients. Also controindieated with known hypersensitivity to any of its ingredients. Also contraindicated in paon MAO inhibitor therapy. Should not be used during pregnaney or patient on MAO in

Considerable caution should be exercised in patients with hypertension, diabetes mellitus, ischemic heart disease, hyperthyroidism, increased intraocular pressure and prostatic hypertrophy. The elderly (60 years or older) recommended recommended dose, nervousses, dlzziness or sleeplessness may occur. PRECAUTIONS: General: Caution should be exercised in patients with high blood pressure, heart disease, diabetes or thyrold disease and in patient who exhibit difficulty in urination due to enlargement of the prostate gland Check with a physician if symptoms do not improve within 7 days or if accompanied by high fever, rash or persistent headache.

Drug Interactions: Do not take this product if you are presently taking a prescription drug for high blood pressure or depression without first consulting a physician. MAO inhibitors and beta adrenergic blockers may increase the effect of sympathomimetics. Sympathomimetics may reduce the antihypertensive effects of methyldopa, mecamylamine, reserpine and veratrum alkaloids. Pseudoephedrine hydrochloride may increase the possibility of cardiac arrhythmias in patients presently taking digitalis glycosides.

Pregnancy: Pregnancy Category B. It has been shown that pseudoephedrine hydrochloride can cause reduced average weight, length, and rate of skeletal ossification in the animal fetus.

Nursing Mothers: Pseudoephedrine is excreted in breast milk; use by nursing mother is not recommended because of the higher than usual risk of side ef fects from sympathomimetic amines for infants, especially newborn and premature infants.

Geriatrics: Pseudoephedrine should be used with caution in the elderly because they may be more sensitive to the effects of the sympathomimetics. WARNINGS: Do not take this product for persistent or chronic cough such as occurs with smoking, asthma, or emphysema, or where cough is accompanied by excessive secretions except under the advice and supervision of a physician. This medication should be taken a few hours prior to bedtime to minimize the posibility of sleeplessness. Take this medication with a glass of water after each dose, to help loosen mucus in the lungs.

ADVERSE REACTIONS: Adverse reactions include nausea, cardiac palpitations, increased irritability or excitement, headache, dizziness, tachycardia diarrhea, drowsiness, stomach pain, seizures, slowed heart rate, shortness of breath and/or troubled breathing.

OVERDOSAGE: KEEP THIS AND ALL DRUGS OUT OF THE REACH OF CHILDREN. IN CASE OF SUSPECTED OVERDOSE, IMMEDIATELY CALL YOUR REGIONAL POISON CONTROL CENTER and/or SEEK PROFESSIONAL ASSISTANCE.

Symptoms of overdosage may be caused by pseudoephedrine. Symtoms of overdosage with pseudophedrine include anxiety, tenseness, respiratory difficulty, headache and awareness of the slow forceful heartbeat.

TREATMENT OF OVERDOSE: The stomach should be emptied promptly by emetics and/or gastric lavage. The installation of activated charcoal also should be considered. Cardiac function and serum electrolytes should be monitored and treatment instigated if indicated. If convulsions or marked CNS excitement occurs, diazepam may be used.

DOSAGE AND ADMINISTRATION: GUAIFED ${ }^{\circ}$ CAPSULES. Adults and children over 12 years of age: 1 capsule orally every 12 hours.

GUAIFED ${ }^{\circ}$-PD CAPSULES. Adults and children over 12 years of age: 1 or 2 capsules orally every 12 hours. Children 6 to 12 years of age -1 capsule orally every 12 hours.

HOW SUPPLIED: GUAIFED ${ }^{*}$ CAPSULES. Bottle of 100 (NDC 0451-4002-50). Each capsule is coded "GUAIFED" "MURO 120-250". GUAIFED $^{\circ}$-PD CAPSULES, Bottle of 100 (NDC 0451-4003-50). Each capsule is coded "GUAIFED-PD" "MURO 60-300"

Dispense in tight containers as defined in USP. Store at controlled room temperature, between $15^{\circ}-30^{\circ} \mathrm{C}\left(59^{\circ}-86^{\circ} \mathrm{F}\right)$

Dispense in child resistant container.

Keep this and all drugs out of reach of children.

CAUTION: FEDERAL (U.S.A.) LAW PROHIBITS DISPENSING WITHOUT A PRESCRIPTION.
Medical Center added 6,000 mg. of MSG-or 10 times the amount consumed in a meal-to soft drinks. Six patients who had complained of past adverse reactions to MSG were tested in a doubleblind fashion in 4 separate trials. Two of the participants reported reactions to both the MSG drink and the MSG-free soda. The remaining 4 participants had no response to either solution.

\section{A cancer and research center is benefiting} from an improbable source-the sale of cigarettes. Construction of the 162-bed facility, which is linked with the University of South Florida's College of Medicine, is being funded in part by Florida's cigarette tax. The center will focus exclusively on cancer research, education, and treatment, in the state that leads the nation in cancer incidence and mortality, with almost 50,000 cases a year and 25,000 annual deaths.

\section{Medical malpractice is ranked as one of the} top health issues facing state legislatures today, according to a recent survey by the National Conference of State Legislatures. Proposed laws on the problem are now considered likely in 31 states. But will these laws have any true impact on the malpractice crisis? Recent history shows that the answer may be a resounding "yes."

For example, in 1974 the average jury award in California was $\$ 133,817$, or 80.5 percent of the national average of $\$ 166,165$. A law that limited attorney's contingency fees allowed periodic payment of awards, and capped noneconomic damages was passed the following year. By 1984, the average award increased to just $\$ 396,662$ - or 41.5 percent of the $\$ 954,858$ national average. Indiana and Nevada have had success with pretrial screening panels of malpractice cases.

The November elections are behind us. It is hoped that the newly elected officials will respond to the urgent need for tort reform.

New guidelines for protecting children from head entrapment injuries have just been issued by the Consumer Products Safety Commission. According to data compiled by the CPSC, in more than 470 child accidents involving head entrapment, 341 deaths resulted from strangulation in product structures and openings. Therefore, to promote safer designs in such household products, the CPSC has completed a 2-year study measuring the size and shape of children's heads and necks.

Until new safety standards are adopted, all re- 
sponsible adults should be alerted to the following hazards: “(1) Entrapment between the guardrails attached to a regular-sized bed, whereby the feet and body slide through but the head is trapped; (2) head entrapment between a bed and a wall or another bed; (3) entrapment between crib slats in older cribs where the openings allow the body of small infants to pass through but not the head; (4) entrapment in decorative "cutouts" in crib or bed headboards, particularly if the opening narrows at the bottom to form a notch; (5) entrapment in the loose mesh pocket formed by the side of a playpen that was accidentally lowered; (6) entrapment in a toy chest caused by a hinged lid falling and striking the back of the child's head; (7) entrapment in one of the V-shaped openings along the top edge of an expandable gate or enclosure when a child tries to climb over the top; (8) entrapment in the diamondshaped openings in a safety gate or enclosure; (9) entrapment in heavy, collapsible recliner chairs, especially between the footrest and the chair cushion; (10) entrapment between the rungs of play ladders; (11) entrapment between the vertical slats in wooden chair backs; and (12) entrapment beneath an electrically operated garage door as it is closing."

Breast tumors grow more rapidly in younger than in older women, according to a 10-year study of 10,530 women by Myron Moskowitz, M.D., of the Breast Consultation Service, University of Cincinnati. Thus, shortening the time interval between screenings may help improve breast cancer survival rates in younger patients.

Current guidelines recommend baseline clinical and mammographic examinations at 40 years of age followed by biennial screenings; annual mammography is recommended only for women over 50 . Dr. Moskowitz, writing in the October 1986 issue of Radiology, suggests that the guidelines be restructured. He recommends that women aged 40 to 49 should have yearly mammographic and clinical examinations, with biennial screenings for women 50 years or older.

Call it a mother's intuition, but for years, parents of children with asthma have suspected that the medication given to control their child's shortness of breath, wheezing, and coughing caused moodiness, hyperactivity, anxiety, and learning problems in school. Now, a study in the December 1986 issue of Pediatrics confirms that even short-term use of theophylline is responsible for these behavioral changes.
"We know that long-term use of theophylline can stimulate the central nervous system, which means nervousness, restlessness, tremors, insomnia, muscle incoordination, and speech disturbances," commented Gary S. Rachelefsky, M.D., the primary author of the report. "This study shows that even short-term use of this drug can severely affect learning and behavior."

Many physicians continue to use theophylline. However, several newer drugs have been added to the physician's armamentarium. One such drug, cromolyn sodium, is attracting fresh interest in the effort to conquer asthma symptoms with fewer side effects.

Guidelines aimed at protecting the rights of older Americans were developed at a conference sponsored by the American Bar Association's Commission on Legal Problems of the Elderly and the National Judicial College. (However, these recommendations have not yet been presented before the ABA's House of Delegates for official approval.)

The guidelines are intended for judges who are confronted with the complex issues of guardianship for frail older persons. They recommend that neither advanced age alone nor a doctor's medical diagnosis be the sole criterion for incompetency, that judges assign an investigator to assess the elderly person's situation and make appropriate recommendations, that "less restrictive alternatives" be explored before appointing a guardian or conservator, and that efforts be made to enable elderly individuals to be present during court hearings.

Malignant melanoma, which is increasing at a rate of 6 percent per year, is now more common than Hodgkin's disease. At least one sunbelt medical center has responded to the alarming increase by opening a mole and pigmented tumor program.

Besides dispensing treatment, the Stanford University Dermatology Clinic offers commonsense patient advice. For example, people who enjoy sun sports should wear sunscreens and sit in the shade. Sunburn should be avoided in favor of gradual exposure. And blue-eyed, fair-skinned people, who are at higher risk for melanoma, should be especially alert to the danger signs of asymmetric moles, those with irregular borders or multicolors, or any skin growth that has changed size or shape.

Three-dimensional volumetric computed tomography (CT) bone densitometry is the latest technique for measuring the density of the femur 


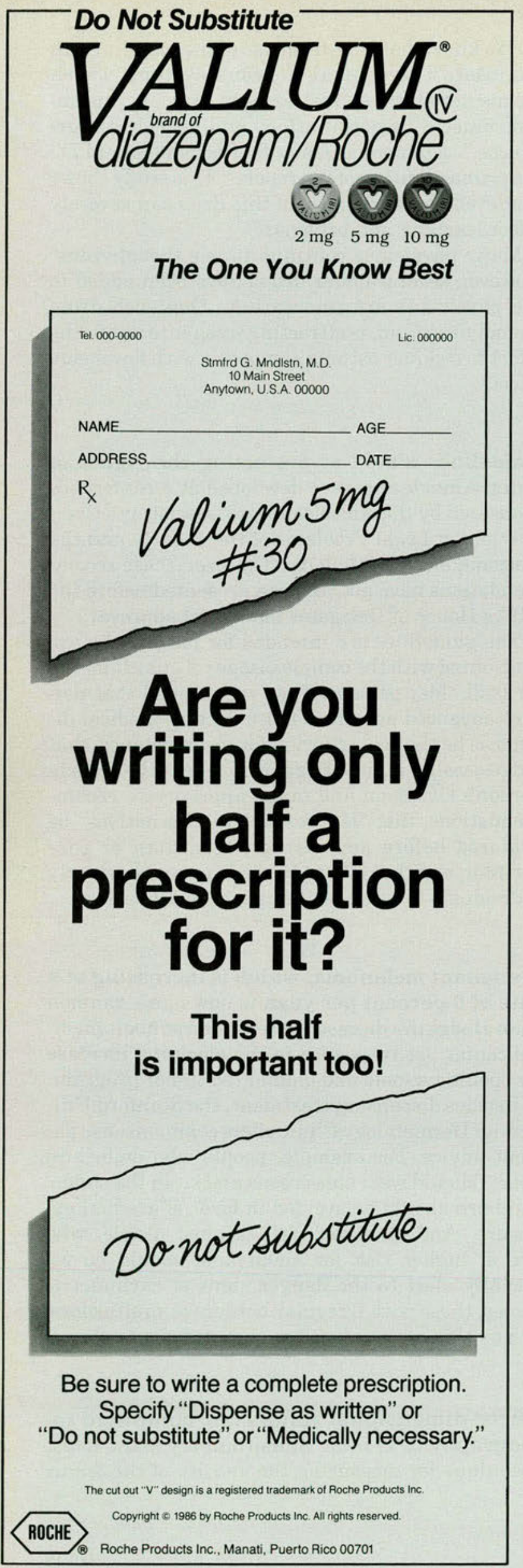

and accurately assessing subtle changes in bone mass.

The procedure, which was developed by scientists at the University of California at San Diego, involves less radiation than conventional $x$-rays and utilizes the CT equipment that many hospitals already own. Previous attempts to use CT failed because of difficulties associated with the complex geometry and irregular architecture of the femur. The new system uses software that can distinguish between cortical and cancellous bone.

The researchers anticipate that the new 3-D CT technique will be highly useful in early diagnosis, assessment of at-risk individuals, grading of disease, and monitoring and evaluation of treatment. Their report appears in the September 1986 issue of Radiology.

An informal poll was conducted at a recent meeting of the American Association of Neurological Surgeons. As a prelude to a talk on chemonucleolysis therapy for herniated lumbar disk, the speaker asked a large audience, "How many of you have performed this procedure?" Some 300 hands shot up. "How many of you still do it?" Six hands were raised.

This in no way constitutes a final judgment of the procedure. But, as in many cases, early enthusiasm seems to have outstripped reality.

A nationwide study of pain and how people cope with it was conducted by Louis Harris and Associates for the manufacturers of Nuprin.

The report, based on the responses of 1,254 adults, revealed several interesting findings: Americans lose 550 million work days each year because of pain; headaches are the most common complaints; nearly 3 out of 5 adults who experienced more than occasional pain consulted a physician in the past year; young people are more likely to experience pain than elderly persons; those under stress experience more pain and consult doctors more frequently than nonstressed persons; working mothers report more painful events than women who stay at home; and 40 percent of all adult women suffer from premenstrual or menstrual pain. 

For added blood pressure control, a major office-based study shows*...

\section{In the elderly}

regardless of previous therapy

\begin{tabular}{l|rcc}
\hline PREVIOUS & \multicolumn{4}{c}{ Change in BPt } \\
\cline { 2 - 4 } ANTIHYPERTENSIVE THERAPY & \multicolumn{1}{|c}{ S } & Systolic & Diastolic \\
\hline Beta blocker (monotherapy) & 1,206 & -22.9 & -12.43 \\
\hline Diuretic (monotherapy) & 820 & -24.2 & -14.4 \\
\hline Free combination & & & \\
: 2 drugs & 2,346 & -17.8 & -10.2 \\
: 4 drugs & 517 & -17.9 & -9.6 \\
\hline Fixed combination & 142 & -18.7 & -10.8 \\
\hline
\end{tabular}

-TENORETIC Evaluation Program, an open 28-day study of 26,892 hypertensive

patients (data on file, Stuart Pharmaceuticals, Wilmington, Delaware): physicians

entered those patients needing more control than provided by monotherapy.

TENORETIC is not indicated for the initial therapy of hypertension.

tDecreases in blood pressure were statistically significant. 


\section{In the elderly without added side effects}

Total number of older patients treated: 9,098 .

No adverse reactions reported in $89.2 \%$.

Patients reported feeling either better than or as good as before: $94.7 \%$.

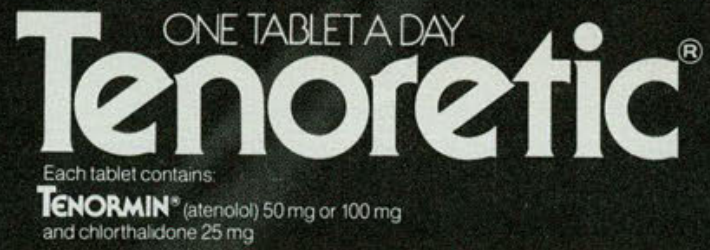

For added control and convenience ...without added side effects. 
For added blood pressure control...

\section{In black males regardless of age*}

\begin{tabular}{|c|c|c|c|}
\hline \multirow[b]{2}{*}{ Age } & \multirow[b]{2}{*}{$\mathrm{n}$} & \multicolumn{2}{|c|}{ Change in $\mathrm{BP}^{\dagger}$} \\
\hline & & Systolic & Diastolic \\
\hline$<40$ & 318 & -18.9 & -14.1 \\
\hline $40-60$ & 828 & -20.5 & -13.9 \\
\hline$>60$ & 322 & -23.9 & -13.7 \\
\hline
\end{tabular}

*TENORETIC Evaluation Program, an open 28-day study of 26,892 hypertensive patients (data on file, Stuart Pharmaceuticals, Wilmington, Delaware): physicians entered those patients needing more control than provided by monotherapy.

TENORETIC is not indicated for the initial therapy of hypertension.

tDecreases in blood pressure were statistically significant. 


\section{And in all patients}

\section{regardless of age, race, sex*}

\begin{tabular}{lc|cc} 
& & \multicolumn{2}{c}{ Change in BP† } \\
\cline { 3 - 4 } Type & $\mathrm{n}$ & Systolic & Diastolic \\
\hline Overall & 26,892 & -20.99 & -13.1 \\
\hline White & 19,185 & -20.9 & -12.9 \\
\hline Black & 3,701 & -21.2 & -13.5 \\
\hline Other & 1,147 & -22.3 & -13.8 \\
\hline Female & 12,540 & -21.6 & -13.1 \\
\hline Male & 11,844 & -20.3 & -13.1 \\
\hline
\end{tabular}

TENORETIC Evaluation Program, an open 28-day study of 26,892 hypertensive patients (data on file, Stuart Pharmaceuticals, Wilmington, Delaware): physicians entered those patients needing more control than provided by monotherapy.

TENORETIC is not indicated for the initial therapy of hypertension.

Decreases in blood pressure were statistically significant 


\section{Tenoretic}

TeNORMIN" (atenolol) $50 \mathrm{mg}$ or $100 \mathrm{mg}$

\section{Added control, added convenience ...without added side effects... regardless of age, race, or sex.}

\section{Please consult complete product information before prescribing.
A summary follows:}

TENORETIC (atenolol and chlorthalidone) is for the treatment of hypertension. It combines the antihypertensive activity of two agents: a beta, selective (cardioselective) hydrophilic blocking agen (atenolol. TENORMIN) and a monosulfonamyl diuretic (chlorthalidone)

INDICATIONS AND USAGE: TENORETIC is indicated for the treatment of hypertension. This fixeddose combination drug is not indicated for initial therapy of hypertension. If the fixed-dose combination represents the dose appropriate to the individual patient's needs, it may be more convenient than the separate components.

CONTRAINDICATIONS: TENORETIC is contraindicated in patients with: sinus bradycardia, heart block greater than first degree, cardiogenic shock, overt cardiac failure (see WARNINGS), anuria, hypersensitivity to this product or to sulfonamide-derived drugs.

WARNINGS: Cardiac Failure: Sympathetic stimulation is necessary in supporting circulatory function in congestive heart failure, and beta blockade carries the potential hazard of further depressing myocardial contractility and precipitating more severe failure. In hypertensive patients who have congestive heart failure controlled by digitalis and diuretics. TENORETIC should be administered cautiously. Both digitalis and atenolol slow AV conduction

In Patients Without a History of Cardiac Failure: Continued depression of the myocardium with beta-blocking agents over a period of time can, in some cases, lead to cardiac failure. At the first sign or symptom of impending cardiac failure, patients receiving TENORETIC should be digitalized and/o
be given additional diuretic therapy. Observe the patient closely. If cardiac failure continues despite be given additional diuretic therapy. Observe the patient closely. If cardiac failure contin

Renal and Hepatic Disease and Electrolyte Disturbances: Since atenolol is excreted via the

kidneys. TENORETIC should be used with caution in patients with impaired renal function In patients with renal disease, thiazides may precipitate azotemia. Since cumulative effects may develop in the presence of impaired renal function, if progressive renal impairment becomes evident. TENORETIC should be discontinued.

In patients with impaired hepatic function or progressive liver disease, minor alterations in fluid and electrolyte balance may precipitate hepatic coma. TENORETIC should be used with caution in these patients

Ischemic Heart Disease: Although not yet reported with atenolol following abrupt cessation of therapy with certain beta-blocking agents in patients with coronary artery disease, exacerbations angina pectoris and, in some cases, myocardial infarction have been reported. Therefore, such patients should be cautioned against interruption of therapy without the physician's advice. Even in
the absence of overt angina pectoris, when discontinuation of TENORETIC is planned, the patient should be carefully observed and should be advised to limit physical activity to a minimum.

NORETIC should be reinstated if withdrawal symptoms occur

Bronchospastic Diseases: PATIENTS WITH BRONCHOSPASTIC DISEASE SHOULD, IN GENERAL, NOT RECEIVE BETA BLOCKERS. Because of its relative beta, - -selectivity, however, TENORETIC may be used with caution in patients with bronchospastic disease who do not respond to, or cannot tolerate, other antihypertensive treatment. Since beta $1_{1}$-selectivity is n agent (bronchodilator) should be made avaliable. If dosage must be increased, dividing the agent (bronchodilator) should be made available. If dosage must be increa

Anesthesia and Major Surgery: As with all beta-receptor blocking drugs, it may be decided to Anesthesia and Major Surgery: As with all beta-receptor blocking drugs, it may be decided to
withdraw TENORETIC before surgery. In this case, 48 hours should be allowed to elapse between the withdraw TENORETIC before surgery. In this case, 48 hours should be allowed to elapse between
last dose and anesthesia. If treatment is continued, care should be taken when using anesthetic agents because of the risk of further depression of the myocardium

Beta blockers are competitive inhibitors of beta-receptor agonists and their effects on the heart can be reversed by administration of such agents; eg, dobutamine or isoproterenol with caution (see hypotension) may be corrected with atropine (1-2 mg IV)

Metabolic and Endocrine Effects: TENORETIC may be used with caution in diabetic patients. Beta blockers may mask tachycardia occurring with hypoglycemia, but other manifestations such as Beta blockers may mask tachycardia occurring with hypoglycemia, but other manifestations such as
dizziness and sweating may not be significantly affected. Atenolol does not potentiate insulin-induced hypoglycemia and, unlike nonselective beta blockers, does not delay recovery of blood glucose to

Insulin requirements in diabetic patients may be increased. decreased, or unchanged; latent iabetes mellitus may become manifest during chlorthalidone administration.

Beta-adrenergic blockade may mask certain clinical signs (eg. tachycardia) of hyperthyroidism. Abrupt withdrawal of beta blockade might precipitate a thyroid storm, therefore, patients suspect
developing thyrotoxicosis and from whom TENORETIC therapy is to be withdrawn should be
monitored closely.

Because calcium excretion is decreased by thiazides. TENORETIC should be discontinued before carrying out tests for parathyroid function. Pathologic changes in the parathyroid glands, with hypercalcemia and hypophosphatemia, have been observed in a few patients on prolonged thiazide therapy, however, the common complications of hyperparathyroidism such as renal lithiasis, bone

Hyperuricemia may occur or acute gout may be precipitated in certain patients receiving thiazide
therapy. PRECAUTIONS, General-Electrolyte and Fluid Balance Status: Periodic determination of serum Patients should be observed for clinical signs of fluid or electrolyte imbalance, ie, hyponatremia. hypochloremic alkalosis, and hypokalemia. Serum and urine electrolyte determinations are particularly important when the patient is vomiting excessively or receiving parenteral fluids. Warning signs or symptoms of fluid and electrolyte imbalance include dryness of the mouth, thirst, weakness. lethargy, drowsiness, restlessness, muscle pains or cramps, muscular fatigue, hypotension, oliguria. tachycardia, and gastrointestinal disturbances such as nausea and vomiting.

tachycardia, and gastrointestinal disturbances such as nausea and vomiting.
Hypokalemia may develop, especially with brisk diuresis, when severe cirrh

Hypokalemia may develop, especially with
concomitant use of corticosteroids or ACTH.

Interterence with adequate oral electrolyte intake will also contribute to hypokatemia can sensitize or exadequate oral electrolyte intake will also contribute to hypokalemia. Hypokalem ventricular irritability). Hypokalemia may be avoided or treated by use of potassium supplements or lods with a high potassium content

Any chloride deficit during thiazide therapy is generally mild and usually does not require specific nal disease) Dilutional hyponatremia may occur in edematous patients in hot weather, appropriate therapy is water restriction
rather than administration of salt except in rare instances when the hyponatremia is life-threatening. In rather than administration of salt except in rare instances when the hyp

Drug Interactions: TENORETIC may potentiate the action of other antihypertensive agents used

concomitantly. Patients treated with TENORETIC plus a catecholamine depletor (eg, reserpine) should be closely observed for evidence of hypoten
vertigo, syncope, or postural hypotension.

vertigo, syncope, or postural hypotension.
Thiazides may decrease arterial responsiveness to norepinephrine. This diminution is not sufficient

to preclude the therapeutic effectiveness of norepinephrine. Thiazides may increase the

responsiveness to tubocurarine.
Lithium generally should not be given with diuretics because they reduce its renal clearance and add a high risk of lithium toxicity. Read circulars for lithium preparations before use of such Dith TENORETIC.

Should it be decided to discontinue therapy in patients receiving TENORETIC and clonidine concurrently, the TENORETIC should be discontinued several days before the gradual withdrawa onidine.

Other Precautions: In patients receiving thiazides, sensitivity reactions may occur with or witho history of allergy or bronchial asthma. The possible exacerbation or activation of systemic lupus erythe postsympathectomy patient

Carcinogenesis, Mutagenesis, Impairment of Fertillty: Two long-term (maximum dosing durat (maximum dosing duration of 18 months) mouse study with atenolol, each employing dose levels as high as $300 \mathrm{mg} / \mathrm{kg} /$ day or $150 \mathrm{~m}$

Atenolol was negative in the mouse dominant lethal test, the Chinese hamster in vivo cytogenetic test and the Salmonella typhimurium back mutation test (Ames test), with or without metabolic activation.

Fertility of male or female rats (evaluated at dose levels as high as $200 \mathrm{mg} / \mathrm{kg} /$ day or 100 times th (

Use in Pregnancy: Pregnancy Category C. TENORETIC (atenolol and chlorthalidone) was studie

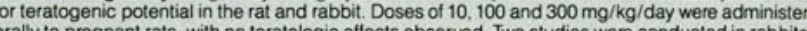

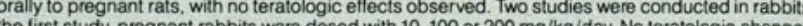
5.10 to 100 times the maximum recommende that the $25 \mathrm{mg} / \mathrm{kg} /$ day. No teratogenic or en that the no-eflect level for embryonic resorptions is $25 \mathrm{mg} / \mathrm{kg} / \mathrm{day}$ (approximately 12.5 times the only if the potential benefit justifies the potential risk to the fetus.

Atenoloj-Atenolol has been shown to produce a dose-related increase in embryo/fetal resorptio in rats at doses equal to or greater than $50 \mathrm{mg} / \mathrm{kg}$ or 25 or more times the maximum recommended rabbits at doses above $25 \mathrm{mg} / \mathrm{kg}$ or 12.5 times the maximum recommended human dose. There are
res no adequate and well-controlled studies in pregnant women.

Chlorthalidene- Thiazides cross the placental barrier and appear in cord blood. The use of . The anticipated benefits of the $d r$ e weighed against possible hazards to the fetus. These hazards include fetal or neonatal jaundice Nursocytopenia, and possibly other adverse reactions which have occurred in the adult.

Nursing Mothers: It is not established to what extent this drug is excreted in human milk. Since most drugs a

Pediatric Use: Safety and effectiveness in children have not been established

ADVERSE REACTIONS: TENORETIC is usually well tolerated in properly selected patients. Most adverse effects have been mild and transient. The adverse effects observed for TENORETIC are essentially the same as those seen with the individual components

Atenolol: The frequency estimates that follow derive from controlled studies in which adverse reactions were either volunteered by the patient (US studies) or elicited, eg. by checklist (foreign studies). The reported frequency of elicited adverse effects was higher for both atenolol and placeb treated patients than when these reactions were volunteered. Where frequenc

atenolol and placebo is similar, causal relationship to atenolol is uncertain.

The data present these estimates in terms of percentages: first from the US studies (volunteered

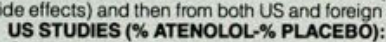

CARDIOVASCULAR: bradycardia ( $3 \%-0 \%)$, cold extremities ( $0 \%-0.5 \%)$, postural hypotension (2\%-1\%), leg pain $(0 \%-0.5 \%$

CENTRAL NERNOUS SYSTEM/NEUROMUSCULAR: dizziness ( $4 \%-1 \%)$, vertigo (2\%-0.5\%), lightheadedness $(1 \%-0 \%)$, tiredness $(0.6 \%-0.5 \%)$, fatigue $(3 \%-1 \%$

GASTROINTESTINAL: diarrhea $(2 \%-0 \%$ ), nausea $(4 \%-1 \%)$

RESPIRATORY (See WARNINGS): wheeziness ( $0 \%-0 \%)$, dyspnea $(0.6 \%-1 \%$ )

TOTALS US AND FOREIGN STUDIES:

$(4 \%-5 \%)$, leg pain $(3 \%-1 \%)$

作 2\%-0.5\%) d d $0.7 \%)$, tiredness $(26 \%-13 \%)$, fatigue

GASTROINTESTINAL: diarthea $(3 \%-2 \%)$, nausea $(3 \%-1 \%)$

RESPIRATORY (see WARNINGS): wheeziness $(3 \%-3 \%)$, dyspnea $(6 \%-4 \%)$

MISCELLANEOUS: There have been reports of skin rashes and/or dry eyes associated with the us of beta-adrenergic blocking drugs. The reported incidence is small and, in most cases, the sympton have cleared when treatment was withdrawn. Discontinuance of the drug should be considered if an
such reaction is not otherwise explicable. Patients should be closely monitored following cessation therapy

Chlorthalidone: Cardiovascular: orthostatic hypotension; Gastrointestinal: anorexia, gastric irritation vomiting, cramping. constipation, jaundice (intrahepatic cholestatic jaundice), pancreatitis; CNS vertigo, paresthesias, xanthopsia: Hematologic: leukopenia, agranulocytosis, thrombocytopenia aplastic anemia: Hypersensitivity: purpura, photosensitivity, rash, urticaria, necrotizing angitis (vasculitis, cutaneous vasculitis), Lyell's syndrome (toxic epidermal necrolysis); Miscellaneous hyperglycemia, glycosuria, hyperuricemia, muscle spasm, weakness, restlessness. Clinical trials of
TENORETIC conducted in the United States (89 patients treated with TENORETIC) revealed no new

Potential Adverse Effects: In addition, a variety of adverse effects not observed in clinical trials with atenolol but reported with other beta-adrenergic blocking agents, should be considered poten adverse effects of atenolol. Nervous System: reversible mental depression progressing to cataton hallucinations; an acute reversible syndrome characterized by disorientation for time and place. short-term memory loss, emotional lability, slightly clouded sensorium, decreased performance neuropsychometrics; Cardiovascular: intensification of AV block (see CONTRAINDICATIONS): Gastrointestinal; mesenteric arterial thrombosis. ischemic colitis; Hematologic: agranulocytosis. nonthrombocytopenic purpura, thrombocytopenic purpura; Allergic: erythematous rash, fever
combined with aching and sore throat, laryngospasm and respiratory distress: Miscellaneous: reversible alopecia, Peyronie's disease.

There have been reports of a syndrome comprising psoriasiform skin rash, conjunctivitis sicca, otitis, and sclerosing serositis attributed to the beta-adrenergic receptor blocking agent, practolo. This syndrome has not been reported with TENORETIC or TENORMIN (atenolol).

Clinical Laboratory Test Findings: Clinically important changes in standard laboratory parameters were rarely associated with the administration of TENORETIC. The changes in laborator
parameters were not progressive and usually were not associated with clinical manifestations. The most common changes were increases in uric acid and decreases in serum potassium. DOSAGE AND ADMINISTRATION: Initial dose should be one TENORETIC 50 tablet once a day. If optimal response is not achieved, the dosage should be increased to one TENORETIC 100 table: once a day. Package insert should be consulted for dosage adjustments in cases of severe impairment of renal function.

HOW SUPPLIED: TENORETIC 50 Tablets (atenolol $50 \mathrm{mg}$ and chlorthalidone $25 \mathrm{mg}$ ). NDC 0038-011 (white, round, biconvex, uncoated tablets with TENORETIC 50 on one side and Stuart 115 on the other side) are supplied in bottles of 100 tablets. TENORETIC 100 Tablets (atenolol $100 \mathrm{mg}$ and chlorthalidone $25 \mathrm{mg}$ ). NDC $0038-0117$ (white, round, biconvex, uncoated tablets with
100 on one side and Stuart 117 on the other side) are supplied in bottles of 100 tablets. Protect from heat, light, and moisture. Dispense in well-closed, light-resistant containe Inactive ingredients: magnesium stearate, microcrystalline cellulose, povidone, sodium starch
glycolate. 